Non-peer reviewed preprint submitted to EarthArXiv, under review at Elementa: Science of the Anthropocene

\title{
Single-blind test of airplane-based hyperspectral methane detection via controlled releases
}

\author{
Evan D. Sherwin ${ }^{1, \dagger, *}$, Yuanlei Chen ${ }^{1, \dagger}$, Arvind P. Ravikumar $^{2}$, Adam R. Brandt ${ }^{1}$
}

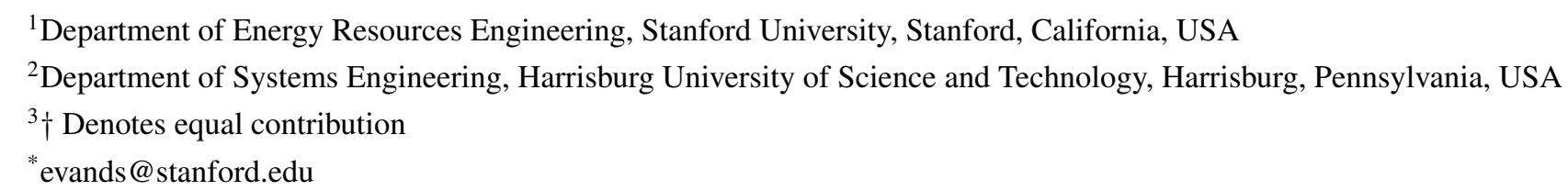

\section{Abstract}

Methane leakage from point sources in the oil and gas industry is a major contributor to global greenhouse gas emissions. The majority of such emissions come from a small fraction of "super-emitting" sources. We evaluate the emission detection and quantification capabilities of Kairos Aerospace's airplane-based hyperspectral imaging methane emission detection system. In blinded controlled releases of methane conducted over four days in San Joaquin County, California, USA, Kairos detected 182 of 200 valid nonzero releases, including all 173 over 15 kilograms per hour of methane $\left(\operatorname{kgh}\left(\mathrm{CH}_{4}\right)\right)$ per meter per second (mps) of wind and none of the 12 nonzero releases below $8.3 \mathrm{kgh}\left(\mathrm{CH}_{4}\right) / \mathrm{mps} .9$ of the 26 releases in the partial detection range of 5 to $15 \mathrm{kgh}\left(\mathrm{CH}_{4}\right) / \mathrm{mps}$ were detected. There were no false positives: Kairos did not detect methane during any of the 21 negative controls. Plume quantification accuracy depends on the wind measurement technique, with a parity slope of $1.15\left(\sigma=0.037, R^{2}=0.84, \mathrm{~N}=185\right)$ using a cupbased wind meter and $1.45\left(\sigma=0.059, R^{2}=0.80, \mathrm{~N}=157\right)$ using an ultrasonic anemometer. Performance is comparable even with only modeled wind data. Quantification error scales roughly as a fixed percentage of emission size. These findings suggest that at $2 \mathrm{mps}$ winds under favorable environmental conditions in the US, Kairos could detect and quantify over $50 \%$ of total emissions by identifying super-emitting sources.

\section{Introduction}

US natural gas (NG) production reached 110 billion cubic feet per day (bcfd) in August 2019, a 56\% increase over the past decade EIA (2019). The shift from coal toward less carbon-intensive NG and renewables has reduced the carbon intensity of the US power sector Schivley et al. (2018). However, the climate benefits of NG cannot be fully realized if methane leaks into the atmosphere at significant rates, as methane has a global warming potential that is 28-36 times that of carbon dioxide over a 100-year period EPA (2017).

The US Environmental Protection Agency (EPA) greenhouse gas inventory states that NG and petroleum systems accounted for $32 \%$ of total US methane emissions and about $4 \%$ of total US greenhouse gas emissions in 2017 EPA (2019). Field surveys in gas-producing regions suggest that the EPA inventory underestimates NG methane emissions, likely because EPA's process-based approach does not sufficiently account for emissions from extremely large sources Brandt et al. (2014); Lyon et al. (2016); Zavala-Araiza et al. (2015). Emission sizes in the North American NG supply chain are found to follow a heavy-tailed distribution, where the top 5\% of point sources, so-called "super-emitters", contribute over 50\% of total emissions Brandt et al. (2014). A recent study indicates that $10 \%$ of the methane point 
Non-peer reviewed preprint submitted to EarthArXiv, under review at Elementa: Science of the Anthropocene

sources in California, including oil and gas facilities, landfills, wastewater treatment plants, and dairy manure management sites, are responsible for $60 \%$ of the detected point-source emissions Duren et al. (2019). Therefore, leak detection and repair (LDAR) programs could reduce the cost of detection and mitigation by allowing mitigation efforts to focus on the largest sources. Given the limited resources and manpower available for detection and repair, technologies for rapidly and accurately identifying superemitters are essential for guiding mitigation efforts.

Close-range approaches, such as optical gas imaging, are widely employed in ground-based LDAR programs in the oil and gas industry. These methods are effective for source identification Ravikumar et al. (2018), but can be slow and labor-intensive. Mobile systems with sensors placed on trucks, drones, or aircraft have the potential advantage of speeding up detection by avoiding the need for manual detection via in-person site visits Ravikumar et al. (2019). In particular, mobile remote sensing via airplanes or satellites can be used to target super-emitters, providing benefits of "low per-site cost, high spatial coverage, and frequent sampling" Fox et al. (2019).

We examine a system developed by Kairos Aerospace (henceforth "Kairos"). Kairos' LeakSurveyor is a hyperspectral methane imaging system that is mounted on a light aircraft flown at general aviation altitudes of approximately $900 \mathrm{~m}$ (3,000 feet) above ground level. The system uses an infrared imaging spectrometer to detect methane, an optical camera to create an optical surface map of the surveyed region, and GPS and inertial measurement units to record the position and orientation of the sensor Kairos (2019). This system is capable of surveying roughly 400 square kilometers (150 square miles) of oil and gas infrastructure in a single day Kairos (2019). See Supplementary Information (SI) section S1 for further detail.

This study performs large-volume single-blind controlled releases, motivated in part by the Mobile Monitoring Challenge (MMC), organized by the Stanford Natural Gas Initiative and the Environmental Defense Fund (EDF). The 2018 MMC tested ten methane detection technologies through single-blind controlled releases, with 6 out of the 10 participating technologies "correctly detecting over $90 \%$ of test scenarios (true positive plus true negative rates)" Ravikumar et al. (2019).

In contrast, we focus on characterizing quantification accuracy of the super-emitting methane point sources that Kairos' technology was designed to quickly identify through aerial surveys. As a result, our emission rates are two to three orders of magnitude larger than those in the $\mathrm{MMC}$, reaching over 1,000 kilograms of methane per hour $\left(\operatorname{kgh}\left(\mathrm{CH}_{4}\right)\right)$, as opposed to $0.29 \mathrm{kgh}\left(\mathrm{CH}_{4}\right)$ for most near-ground technologies in the MMC and $29 \mathrm{kgh}\left(\mathrm{CH}_{4}\right)$ for two airplane and truck-based technologies Ravikumar et al. (2019).

\section{Materials and Methods}

\section{Airplane-based methane sensing technology}

Kairos' methane detection technology uses hyperspectral imaging from the wing of a small aircraft to construct a two-dimensional image of methane concentrations integrated along the path between the airplane and the ground. Each image is generated through a single pass over an area. Kairos' automated processing identifies methane plumes and calculates a wind-adjusted methane emission rate in kilograms of methane per hour per meter per second of wind $\left(\mathrm{kgh}\left(\mathrm{CH}_{4}\right) / \mathrm{mps}\right.$, henceforth denoted $\left.\mathrm{kgh} / \mathrm{mps}\right)$. Note that the spectrometer detects only methane and not other constituent components of natural gas, such as ethane. See the SI, section S1 for further technical detail.

\section{Test location and set-up}

The Stanford team performed four days of single-blind controlled releases in San Joaquin County, California, on October 8th, 10th, 11th, and 15th, 2019. Kairos personnel were in the aircraft but were not 
Non-peer reviewed preprint submitted to EarthArXiv, under review at Elementa: Science of the Anthropocene

present at the ground release site. Stanford personnel designed the methane release schedule and controlled the release rates with assistance from a natural gas release operator, Rawhide Leasing.

We measured methane flow rates through Sierra Instruments QuadraTherm 740i thermal mass flow meters Sierra (2019). We measured wind speed and direction using both a Vantage Vue Sensor Suite with a cup-based wind meter and a Gill Instruments WindSonic 60 two-dimensional ultrasonic anemometer (not present on the first day of data collection) Davis (2018); Gill (2019). See the SI, Section S2 for further detail.

\section{Single-blind experimental design}

The aerial test used a two-person airplane occupied by one pilot and one Kairos engineer, with Kairos' LeakSurveyor instrument fastened to one wing strut. The Kairos engineer oversaw operations and radio communication with ground crews from Stanford and Rawhide. As the aircraft passed over the test site, the Kairos instrument attempted to detect any methane below. The aircraft flew repeated North-South round-trip passes on a fixed route, passing overhead roughly every four minutes, varying from three to five minutes depending on wind and other environmental conditions.

Kairos did not have access to data collected on the ground until they reported final results to Stanford on October $24^{\text {th }}$. Kairos then received actual release rates and ground-based wind measurements on October $29^{\text {th }}$. See the SI, Section S3 for further detail.

\section{Performance metrics}

We test Kairos' technology for detection accuracy, minimum detection threshold, and quantification accuracy. Here, detection accuracy is defined as the sum of true positive and true negative rates. The minimum detection threshold analysis characterizes both the minimum release rate that the technology can detect with some nonzero probability and the rate above which all releases are detected. Quantification accuracy compares the estimated methane release rates to the true release rate. We compute quantification accuracy using a linear fit of released v. detected methane to assess the accuracy of the detection method. For simplicity and intercomparability with other controlled release tests of methane detection technologies, we use an ordinary least squares linear regression in the main analysis, although we discuss the potential implications of weighted least squares approaches that account for variation in uncertainty across points in the SI, Section S9.

\section{Results}

\section{Data summary}

A total of 230 data points were collected during the four-day single-blind tests, among which $21(\sim 9 \%)$ were negative controls during which no methane was released. 40 releases $(\sim 17 \%)$ were dedicated to characterizing the detection threshold by releasing at a rate between $0-50 \mathrm{kgh}$. The remaining large releases ( $\sim 74 \%$ of releases) were focused on testing the ability of the system to quantify high release volumes. Among these, 110 releases were within the range of 50 and $500 \mathrm{kgh}$; and 59 were over $500 \mathrm{kgh}$. Note that reported methane flow rates are 93.5\% of metered natural gas flow rates PG\&E (2019). The volume rates are converted to mass rates based on the molar mass of methane and the molar volume at the standard condition of $1 \mathrm{~atm}$ and $15{ }^{\circ} \mathrm{C}$ GPSA (2011).

Of the 230 data points collected, we exclude 9 from the baseline analysis due to technical issues such as an incomplete plume image or controlled release practices that deviated from protocol. 4 additional overflights did not result in valid data collection due to an incorrect flight altitude (see the SI, section S2 for details). When using wind speed from the cup meter, we exclude an additional 8 data points from 
the 230 data points with measured 1-minute gust wind speed lower than $0.9 \mathrm{mps}$ ( 2 miles per hour), the rated uncertainty. We also exclude data points from the quantification analysis if there is not sufficient time after a change in release level for full plume development. See the SI, Section S5 for further detail.

Figure 1 shows false color images of methane plumes detected by the Kairos instrument during the trial, with blue and white representing low and high concentrations, respectively. All connected pixels are considered to be within a single plume. If there are multiple disconnected plumes, we consider the closest plume to the release point, consistent with Kairos' internal practices. Figure 1a shows a Kairos image while no methane is being released. Figure $1 \mathrm{~b}$ shows a small plume at a release rate of $36 \mathrm{kgh}$, approaching the minimum detection threshold of the instrument. The plume in Figure 1c is clearly visible, with a wind-adjusted release rate of $87 \mathrm{kgh}$. Figures 1d-f show larger plumes with a wider field of view.

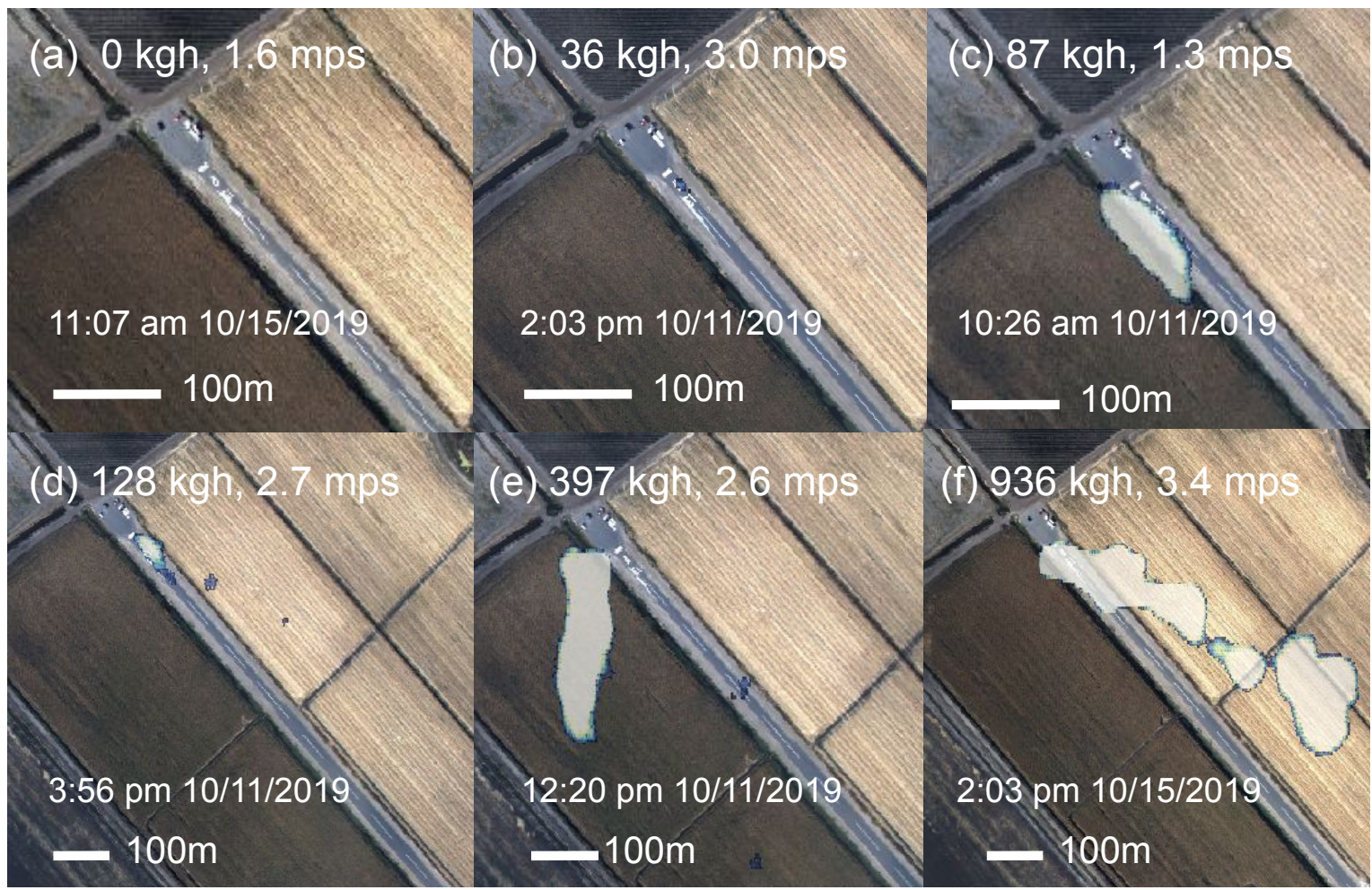

Figure 1. Examples of detected plumes associated with different methane release rates. Plumes are shown in colorized spectrometer images, with blue and white representing low and high concentrations of methane, respectively. Optical images were taken from the airplane as it passed overhead. Each image includes the measured methane release rate, in $\mathrm{kgh}$, and wind speed from the ultrasonic anemometer. Note that the scale changes in the bottom row, d-f. (a) No release. (b) Small release, close to detection threshold. (c) Medium-sized release, low wind. (d) Medium-sized release, moderate wind. (e) Large emission, moderate wind. (f) Approaching maximum release rate, moderate wind.

\section{Detection probability and false positive rate}

Kairos previously published work reporting a 50\% probability of detection at $9.2 \mathrm{kgh} / \mathrm{mps}$ Kairos (2019). Considering the limited resources available for this study and the interest in testing quantification accuracy at large emission rates, only $17 \%$ of data points have nonzero release rates below $50 \mathrm{kgh}$. Due to exclusion criteria and the wind speed conditions at the time of the release, 36 valid data points fall in the range of $0-25 \mathrm{kgh} / \mathrm{mps}$ and are presented in Figure 2. 
Non-peer reviewed preprint submitted to EarthArXiv, under review at Elementa: Science of the Anthropocene

Note that we present results in these wind-normalized units for two reasons. First, Kairos' instrument outputs readings in wind-normalized terms, so this presentation of results disentangles instrument capabilities from the wind profile of the region in question. Second, these releases were on the low end of what our release apparatus could accurately meter. As a result, for many of these smaller releases we left the release level constant and allowed the wind to provide the variability. Thus, converting wind-normalized releases to absolute methane fluxes would remove this variability.

Figure 2 shows the fraction of emissions detected by Kairos as a function of the wind-speednormalized methane release rate for the 35 points below $25 \mathrm{kgh} / \mathrm{mps}$, using 1-minute gust measurements from the cup wind meter. Small circles on the top and bottom of the histogram represent each emission and whether it was detected. Only 1 of the 14 data points in the $5-10 \mathrm{kgh} / \mathrm{mps}$ range was detected, with a true emission rate of $8.3 \mathrm{kgh} / \mathrm{mps}$. The detection rate rises to $67 \%$ for release rates of $10-15 \mathrm{kgh} / \mathrm{mps}$. Above $15 \mathrm{kgh} / \mathrm{mps}, 100 \%$ of emissions were detected, both in this subsample and in the data set as a whole. Thus, the 50\% probability of detection threshold likely occurs between 8.3 and $15 \mathrm{mcfd} / \mathrm{mph}$, consistent with Kairos' internal trials. Error bars represent twice the standard error assuming a binomial distribution, with no error bars shown for cases with $100 \%$ or $0 \%$ detection rates. This suggests that the instrument can detect all emissions above about $15 \mathrm{kgh} / \mathrm{mps}$ with high probability.

Note that due to sensitive manual flow controls and high relative meter error and flow variability at these low flow rates, for this section of the analysis we opted to hold the overall methane release rate relatively constant for extended periods of time, allowing changes in wind speed to provide variability in the wind-normalized release rates that Kairos' method produces. As a result, we characterize the minimum detection threshold in terms of wind-normalized methane release rates but do not have sufficient variability in the overall flow rate to quantify the minimum detection threshold in terms of methane flow rate.

To test for false positives, we devote $\sim 9 \%$ of releases ( 21 releases) to negative controls with release rates of $0 \mathrm{kgh}$. Kairos reported no detections during these periods, leading to a false positive rate of $0 \%$. This is in part because such remote sensing techniques are less sensitive than many other methane detectors, missing small emissions but rarely triggering false positives. Thus, Kairos detected all 173 releases over $15 \mathrm{kgh} / \mathrm{mps}$ and none of the 12 nonzero releases below $8.3 \mathrm{kgh} / \mathrm{mps}$.

In all, Kairos detected 182 of 200 valid nonzero releases and had no false positives in the 21 negative controls, resulting in an overall accuracy of $91.9 \%$, with $100 \%$ accuracy for releases above $15 \mathrm{kgh} / \mathrm{mps}$.

\section{Quantification accuracy}

Figure 3(a) shows 185 valid data points associated with nonzero release rates, comparing the metered release rates (x-axis) to the estimated rates generated by Kairos. For consistency with Kairos' internal testing procedures, we use 1-minute gust wind speed from the cup wind meter to convert the Kairosreported emission estimate in $\mathrm{kgh} / \mathrm{mps}$ to $\mathrm{kgh}$, using wind speed measured at the time of each pass. Kairos reports point estimates with no uncertainty in $\mathrm{kgh} / \mathrm{mps}$. Uncertainties in wind measurements are $\pm \sim 0.9 \mathrm{mps}$ ( \pm 2 mile per hour) for the cup wind meter. This introduces errors in Kairos' estimates of release rates due to uncertainty in wind speed, shown in the Y error bars in Figure 3(a). The length of the error bars is thus dependent on the magnitude of the Kairos-reported number in $\mathrm{kgh} / \mathrm{mps}$. The $\mathrm{y}$-axis of Figure 3(b) shows the Kairos-reported number multiplied by 1-min gust wind speed measured with the ultrasonic anemometer, which has a rated accuracy of roughly $\pm 2 \%$, with some variation depending on wind speed Gill (2019). In this case, the length of the error bars depends both on the magnitude of the measured wind speed and the Kairos-reported quantification in $\mathrm{kgh} / \mathrm{mps}$. Although the ultrasonic anemometer has a much smaller measurement uncertainty, it was not present for the first day of data collection. Therefore, we use results from the cup wind meter, shown in Figure 3(a) as a baseline. See the 
Non-peer reviewed preprint submitted to EarthArXiv, under review at Elementa: Science of the Anthropocene

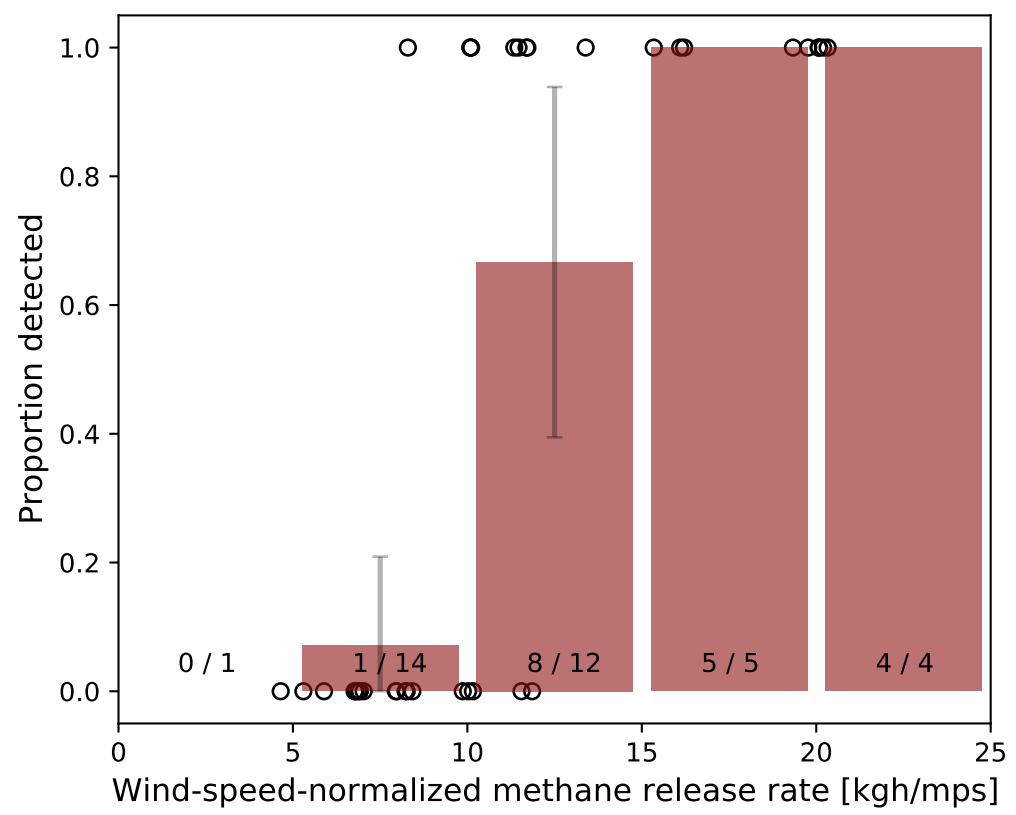

Figure 2. Binary detection results and the proportion of releases detected when the true release rates fall in the range of 0-25 kgh/mps. Each bin has a width of $5 \mathrm{kgh} / \mathrm{mps}$. Kairos detected 100\% of emissions above $15 \mathrm{kgh} / \mathrm{mps}$. The smallest release detected was $8.3 \mathrm{kgh} / \mathrm{mps}$. Error bars show twice the standard error assuming a binomial distribution. The fraction at the bottom of each bin denotes the number of true positives divided by the total number of releases in this range. Small circles on the top and bottom of the histogram represent each emission and whether it was detected.

SI, Section S6 for further detail. See the SI, Section S7 for further detail on uncertainty and variability in the measured natural gas flow rate.

Using winds from the cup wind meter, the linear fit is relatively close to parity, with an $R^{2}$ of 0.84 and a slope of $1.15(\sigma=0.037)$, shown in in Figure 3(a). The slope is statistically distinguishable from zero at the $\mathrm{p}=0.05$ level. This finding is robust to several techniques that correct for heteroskedasticity in the data, shown in the SI, Section S9. Note that the confidence intervals in Figure 3 assume homoskedasticity, which residual plots in Figure S17 suggest does not hold. Heteroskedastic confidence intervals would widen further at higher release rates. Using ultrasonic anemometer wind data, $R^{2}$ drops to 0.80 and the best fit line exhibits a larger slope of $1.45(\sigma=0.059)$, indicating somewhat more bias.

In the field, Kairos may not have access to on-the-ground wind measurements. In these circumstances, one would likely use third-party data products to approximate local wind speed and direction. Figure 3(c) uses 1-minute gust wind reanalysis data from Dark Sky, a private company that estimates minuteresolution wind speed at high spatial resolution across the United States based largely on publicly available data sources and atmospheric modeling Apple (2016). Dark Sky reports wind speed values at $10 \mathrm{~m}$, which we convert to $2.5 \mathrm{~m}$ values using a factor of $(2.5 / 10)^{0.15}$ for grassland terrain, based on BanuelosRuedas et al. (2011). See the SI, Section S5.3.2 for further detail.

Figure 3(d) shows results using hourly surface gust data from the High-Resolution Rapid Refresh (HRRR) wind reanalysis database, produced by the United States National Oceanic and Atmospheric Administration NOAA (2020) averaging wind speed estimates over the nearest $9 \mathrm{~km} \times 9 \mathrm{~km}$ area for the three hours before, during, and after the Kairos measurement, based on Duren et al. (2019). For further 

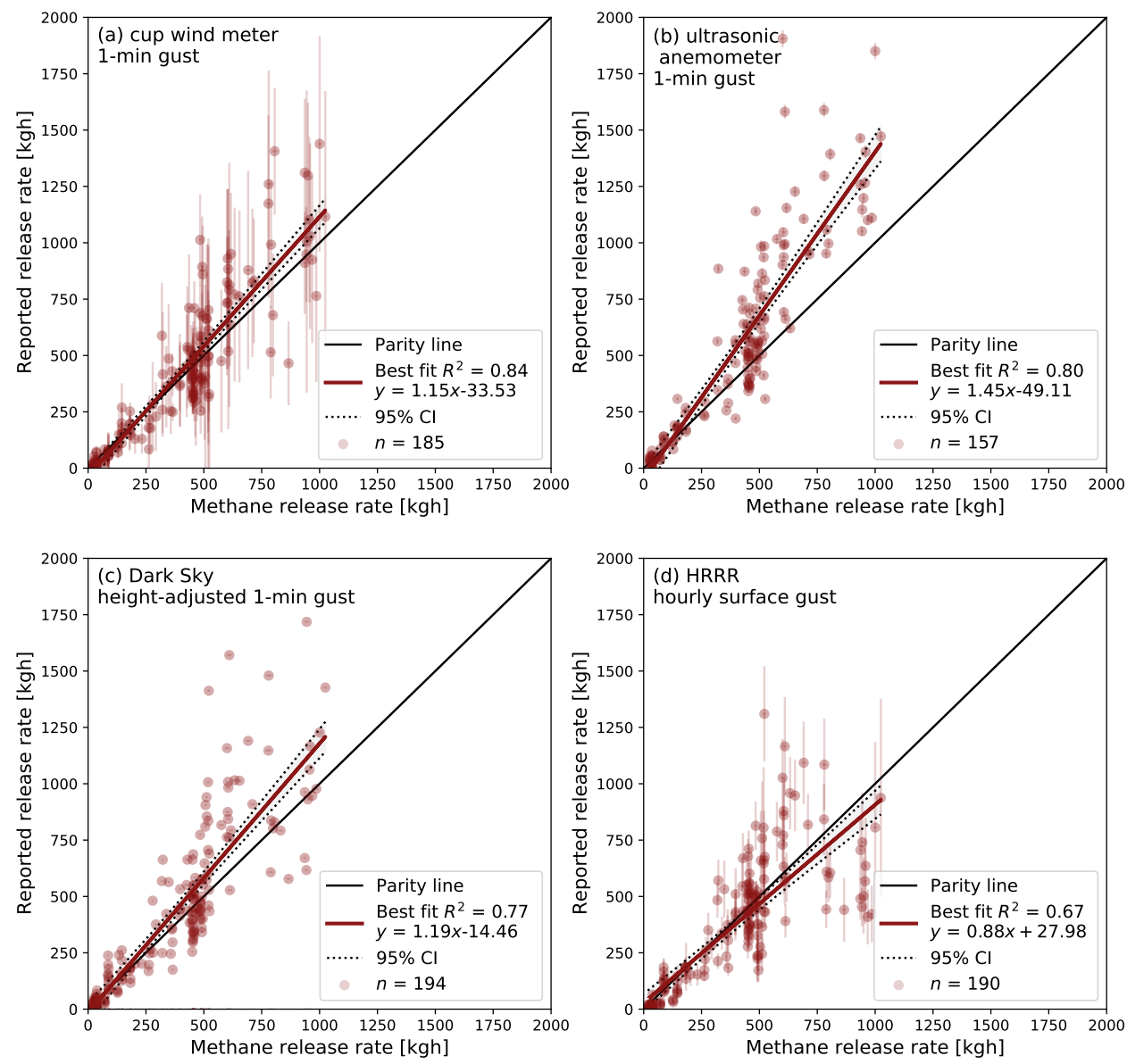

Figure 3. Parity chart of known nonzero methane release rates and the corresponding Kairosreported estimate in $\mathrm{kgh} / \mathrm{mps}$ multiplied by 1-min gust wind speed measured by (a) the cup wind meter, (b) the ultrasonic anemometer or reported by (c) height-adjusted values from the Dark Sky commercial wind reanalysis database, and (d) surface gusts from the High-Resolution Rapid Refresh (HRRR) database. The type of wind used in (a-c) is 1-minute gust wind speed. The $\mathrm{X}=\mathrm{Y}$ parity line indicates perfect quantification. All four cases show a relatively close linear fit. (a-c) show mild to moderate bias toward overestimation based on minutely gust and (d) shows a mild underestimation based on hourly gust. The Dark Sky wind used in (c) is converted to 2.5-meter wind from 10-meter wind by applying a height adjustment factor. The HRRR wind used in (d) uses the method from Duren et al. (2019), averaging hourly surface gusts over three hours in the nearest $3 \times 3$ measurement locations (a box of $9 \mathrm{~km}$ by $9 \mathrm{~km}$ ). See the SI, Section S5.3.2 for further detail on HRRR winds. $95 \%$ confidence intervals of the regression fits are shown. $n=$ number of data points shown in each graph, which depends on data exclusion criteria described in the SI, Section S5.1. Y error bars are based on wind uncertainties, described in the SI, Section S6. X error bars, not visible, are based on observed flow variability and flow meter error, described in the SI, Section S7. 
Non-peer reviewed preprint submitted to EarthArXiv, under review at Elementa: Science of the Anthropocene

discussion of HRRR data, see the SI, Section S5.3.2. Note that (c) and (d) only exclude 6 and 10 data points, respectively due to insufficient time for plume formation, while (a) excludes 15 of 200 nonzero valid data points with either incomplete time for plume formation or wind speed measurements whose uncertainty range contains zero. See the SI, Section S5.1 for further detail.

For both forms of wind reanalysis data, overall quantification performance is similar to the results with ground-based wind data, with a slightly less precise linear fit. With Dark Sky in Figure 3(c), the $R^{2}$ falls slightly to 0.77 with a parity slope of 1.19 , between the cup wind meter and ultrasonic anemometer slopes. The $R^{2}$ for HRRR falls to 0.67 with a slope of 0.88 , indicating average underestimates rather than overestimates of total methane emissions.

Thus, Dark Sky data appears to provide a more precise estimate of overall emissions when groundbased wind data are not available. However, because this is a proprietary product, the underlying algorithms may change without notice. In addition, the data will likely not be publicly available after the end of 2021 Grossman (2020). Although HRRR data have a lower spatial and temporal resolution, the underlying process behind their production is more transparent. In addition, 15-minute HRRR data are available for download within 48 hours of a given date, so future Kairos flights could likely acquire publicly available HRRR data with a higher temporal resolution, potentially improving performance.

Although absolute residual plots in Figure S17(a-b) exhibit heteroskedasticity, percent residuals in Figure S17(c-d) appear relatively stationary in release size. Analysis of the smallest and largest $50 \%$ of the data (above the $100 \%$ detection threshold) demonstrates that the mean and variance are not statistically distinguishable, indicating that it is reasonable to assume that percent measurement error is roughly stationary as methane emission size increases. See the SI, Section S7 for further detail.

These results demonstrate a high level of detector performance, even without on-the-ground wind measurements, in terms of high $R^{2}$ and low bias compared to past controlled releases for mobile methane detectors in Ravikumar et al. (2019); Duren et al. (2019); Schwietzke et al. (2019); Conley et al. (2017) and Foster-Wittig et al. (2015). That said, most controlled release studies operate at one to two orders of magnitude lower release volumes with smaller sample sizes predominantly clustered near the minimum detection threshold and most do not appear to employ a blinded experimental design. See the SI, Section S8 for further detail.

\section{Estimate of field efficacy}

Using a bottom-up inventory of 1,009 methane emission sites from the US oil and gas system from Omara et al. (2018), a compliation of data from nine separate studies and eight oil and gas-producing basins, we estimate that given 2 mps winds and emission detection fractions based on the probabilities from Figure 2, adoption of this technology would detect 53\% of total emissions, with $49 \%$ coming from 24 sites above the $100 \%$ detection threshold of $15 \mathrm{kgh} / \mathrm{mps}$. At $1 \mathrm{mps}$ winds, this rises to $63 \%$ of total emissions. At $4 \mathrm{mps}$ winds, this falls to $41 \%$ of total emissions. At $7 \mathrm{mps}$, the maximum wind speed at which it is safe for these airplane-based surveys, Kairos would still detect $32 \%$ of total emissions. Note that this inventory combines emissions from multiple basins. In practice, detector efficacy would likely vary across basins due to different emission profiles. In addition, we do not perform a full stochastic techno-economic analysis, such as that in the Fugitive Emissions Abatement Simulation Toolkit, which would be necessary to determine the cost-effective mitigation potential of airplane-based methane sensing technology Kemp et al. (2016).

\section{Discussion}

These results suggest that in suitable contexts, aerial surveys at modest wind speeds could detect $50 \%$ or more of total methane emissions even without ground-based wind measurements. This process can 
Non-peer reviewed preprint submitted to EarthArXiv, under review at Elementa: Science of the Anthropocene

screen assets much more rapidly than traditional leak detection and repair methods, with few if any resource-diverting false positives. Thus, this technology could provide rapid detection of super-emitting methane leaks in upstream and midstream oil and gas, likely as a supplement to more precise but more labor-intensive leak detection and repair programs. More sensitive instruments would likely be required for most distribution system applications.

The overall cost of this field trial was roughly $\$ 50,000$ including materials, natural gas release equipment rental, gas, and personnel, flight time, space rental, and miscellaneous expenses (not including Stanford researchers' time). Given that basin-wide or state-wide aerial methane emissions survey campaigns can cost $\$ 1$ million or more, we feel that testing the new instruments with blinded controlled releases at a range of methane emission levels approaching those expected in the field, with a sample size of at least a few dozen, would increase confidence in the capabilities of these methods, thus adding substantial value to the data from such field campaigns.

\section{Contributions}

Substantial contributions to conception and design: EDS, YC, APR, ARB

Acquisition of data: EDS, YC

Analysis and interpretation of data: EDS, YC, ARB

Drafting the article or revising it critically for important intellectual content: EDS, YC, APR, ARB

Final approval of the version to be published: EDS, YC, APR, ARB

\section{Acknowledgement}

The authors would like to thank Jingfan Wang, Jeffrey Rutherford, and Alison L. Marsden at Stanford, and Jeff Gamble and Walter Godsil from Rawhide Leasing for help with the controlled release, as well as Chris Field, Jennifer Johnson, Eric Kort, Keith Andre, and Jon Carlson for their support with wind measurements. We gratefully acknowledge the assistance of Tony Ramirez and the staff of Zuckerman Family Farms.

\section{Funding information}

This study was funded by the Stanford Natural Gas Initiative, an industry consortium that supports independent research at Stanford University. No funding was provided by participating or tested companies.

\section{Competing interests}

The authors have no competing interests to declare

\section{Supplemental material}

The supplemental materials for this article can be found as follows:

- Text S1. Supplementary Information for Single-blind test of airplane-based hyperspectral methane detection via controlled releases. https://osf.io/vqnpb/

- S1. Kairos Aerospace technology

- S2. Controlled release set-up

- S3. Single-blind experimental design

- S4. Methane content and density

- S5. Data exclusion, sensitivity analysis

- S6. Wind variability and uncertainty 
Non-peer reviewed preprint submitted to EarthArXiv, under review at Elementa: Science of the Anthropocene

- S7. Flow variability and uncertainty

- S8. Addressing heteroskedasticity

\section{Data accessibility statement}

All data and code required to reproduce the results of this article are available on GitHub at: https://github.com/yuliachen/Single-blind-test-of-airplane-based-hyperspectral-methane-detection-viacontrolled-releases

\section{References}

Apple. 2016. Dark Sky Data Sources. Apple Inc https://darksky . net/dev/docs/sources.

Banuelos-Ruedas F, Angeles-Camacho C, Rios-Marcuello S. 2011. Methodologies Used in the Extrapolation of Wind Speed Data at Different Heights and Its Impact in the Wind Energy Resource Assessment in a Region. Wind Farm - Technical Regulations, Potential Estimation and Siting Assessment doi:10.5772/20669.

Brandt AR, Heath GA, Kort EA, O'Sullivan F, Petron G, et al. 2014. Methane Leaks from North American Natural Gas Systems. Science 343(6172): 733-735. ISSN 0036-8075, 1095-9203. doi:10.1126/science.1247045. http://www.sciencemag.org/cgi/doi/10.1126/science.1247045.

Conley S, Faloona I, Mehrotra S, Suard M, Lenschow DH, et al. 2017. Application of Gauss's theorem to quantify localized surface emissions from airborne measurements of wind and trace gases. Atmospheric Measurement Techniques 10(9): 3345-3358. ISSN 1867-8548. doi:10.5194/amt-10-3345-2017. https : / www . atmosmeas-tech.net/10/3345/2017/.

Davis. 2018. Vantage Vue Weather Station. Davis Instruments https://www.davisinstruments.com/ product_documents/weather/spec_sheets/6250_6351_57_SS.pdf.

Duren RM, Thorpe AK, Foster KT, Rafiq T, Hopkins FM, et al. 2019. California's methane super-emitters. Nature 575(7781): 180-184. ISSN 0028-0836, 1476-4687. doi:10.1038/s41586-019-1720-3. http://www . nature.com/articles/s41586-019-1720-3.

EIA. 2019. Monthly Crude Oil and Natural Gas Production. US Energy Information Administration (EIA-914). https://www.eia.gov/petroleum/production/\#ng-tab.

EPA. 2017. Greenhouse Gas Emissions: Understanding Global Warming Potentials. US Environmental Protection Agency https: / / www.epa.gov/ghgemissions/understanding-global-warmingpotentials.

EPA. 2019. Inventory of U.S. Greenhouse Gas Emissions and Sinks: 1990-2017. United States Environmental Protection Agency (EPA430-R-19-001). https: / /www .epa.gov/sites/production/files/201904/documents/us-ghg-inventory-2019-main-text.pdf.

Foster-Wittig TA, Thoma ED, Albertson JD. 2015. Estimation of point source fugitive emission rates from a single sensor time series: A conditionally-sampled Gaussian plume reconstruction. Atmospheric Environment 115: 101-109. ISSN 13522310. doi:10.1016/j.atmosenv.2015.05.042. https://linkinghub.elsevier. $\mathrm{com} /$ retrieve/pii/S135223101530114X.

Fox TA, Barchyn TE, Risk D, Ravikumar AP, Hugenholtz CH. 2019. A review of close-range and screening technologies for mitigating fugitive methane emissions in upstream oil and gas. Environmental Research Letters 14(5): 053002. ISSN 1748-9326. doi:10.1088/1748-9326/ab0cc3. https: / / iopscience. iop. org/article/10.1088/1748-9326/ab0cc3.

Gill. 2019. Wind Speed \& Direction Sensor. Gill Instruments http://gillinstruments.com/data/ datasheets/windsonic-1405-027-iss7.pdf.

GPSA. 2011. Section 1 General Information, in Engineering Data Book, 13th Edition (Electronic) Volume I II. United States.

Grossman A. 2020. Dark Sky Has a New Home. Dark Sky. https://blog.darksky . net/. 
Non-peer reviewed preprint submitted to EarthArXiv, under review at Elementa: Science of the Anthropocene

Kairos. 2019. Kairos Aerospace Technical White Paper: Methane Detection. Kairos Aerospace http://kairosaerospace.com/wp-content/uploads/2019/09/Kairos-AerospaceMethane-Detection.pdf.

Kemp CE, Ravikumar AP, Brandt AR. 2016. Comparing Natural Gas Leakage Detection Technologies Using an Open-Source "Virtual Gas Field" Simulator. Environmental Science \& Technology 50(8): 45464553. ISSN 0013-936X, 1520-5851. doi:10.1021/acs.est.5b06068. https : / pubs . acs . org/doi/ 10 . 1021 /acs.est.5b06068.

Lyon DR, Alvarez RA, Zavala-Araiza D, Brandt AR, Jackson RB, et al. 2016. Aerial Surveys of Elevated Hydrocarbon Emissions from Oil and Gas Production Sites. Environmental Science \& Technology 50(9): 48774886. ISSN 0013-936X, 1520-5851. doi:10.1021/acs.est.6b00705. https : / pubs . acs . org/doi/10 . 1021 /acs.est.6b00705.

NOAA. 2020. High Resolution Rapid Refresh (HRRR) CONUS 2-D Fields GRIB2 Table Documentation. National Oceanic and Atmospheric Administration https://rapidrefresh.noaa.gov/hrrr/HRRRv4_ GRIB2_WRETWO.txt.

Omara M, Zimmerman N, Sullivan MR, Li X, Ellis A, et al. 2018. Methane Emissions from Natural Gas Production Sites in the United States: Data Synthesis and National Estimate. Environmental Science \& Technology 52(21): 12915-12925. ISSN 0013-936X, 1520-5851. doi:10.1021/acs.est.8b03535. https://pubs .acs.org/ doi/10.1021/acs.est.8b03535.

PG\&E. 2019. California Gas Transmission | Pipe Ranger | Operating Data | Gas Quality. Pacific Gas and Electric Co https://www.pge.com/pipeline/operations/gas_quality/index.page.

Ravikumar AP, Sreedhara S, Wang J, Englander J, Roda-Stuart D, et al. 2019. Single-blind Inter-comparison of Methane Detection Technologies - Results from the Stanford/EDF Mobile Monitoring Challenge. Elementa: Science of the Anthropocene 7(37): 29. doi:10.1525/elementa.373. https : / www . elementascience. org/articles/10.1525/elementa.373/.

Ravikumar AP, Wang J, McGuire M, Bell CS, Zimmerle D, et al. 2018. "Good versus Good Enough?" Empirical Tests of Methane Leak Detection Sensitivity of a Commercial Infrared Camera. Environmental Science \& Technology 52(4): 2368-2374. ISSN 0013-936X, 1520-5851. doi:10.1021/acs.est.7b04945. https: //pubs.acs.org/doi/10.1021/acs.est.7b04945.

Schivley G, Azevedo I, Samaras C. 2018. Assessing the evolution of power sector carbon intensity in the United States. Environmental Research Letters 13(6): 064018. ISSN 1748-9326. doi: 10.1088/1748-9326/aabe9d. http://stacks.iop.org/1748-9326/13/i=6/a=064018? key= crossref. $5142 \mathrm{~b} 181 \mathrm{a} 7 \mathrm{ebcbef} 80 \mathrm{ae} 62 \mathrm{dccf} 3 \mathrm{~b} 75 \mathrm{fe}$.

Schwietzke S, Harrison M, Lauderdale T, Branson K, Conley S, et al. 2019. Aerially guided leak detection and repair: A pilot field study for evaluating the potential of methane emission detection and cost-effectiveness. Journal of the Air \& Waste Management Association 69(1): 71-88. ISSN 1096-2247, 2162-2906. doi:10.1080/10962247.2018.1515123. https://www.tandfonline.com/doi/full/ $10.1080 / 10962247.2018 .1515123$.

Sierra. 2019. Sierra: QuadraTherm 780i. Sierra Instruments https://www.sierrainstruments.com/ products/quadratherm/780i.html.

Zavala-Araiza D, Lyon DR, Alvarez RA, Davis KJ, Harriss R, et al. 2015. Reconciling divergent estimates of oil and gas methane emissions. Proceedings of the National Academy of Sciences pp. 201522126. ISSN 00278424, 1091-6490. doi:10.1073/pnas.1522126112. http: / / www.pnas.org/lookup/doi/10.1073/ pnas. 1522126112. 